treating shock and other low-flow circulatory states. The subject matter ranges widely from physiological studies like those on venous compliance, cerebral metabolism, and ultrastructural studies on the kidney at necropsy to the effects of prostaglandins, steroids, zymosan, glucagon, and other natural and unnatural agents on treatment. Volume 2 is largely concerned with traumatic, endotoxic, and septic shock, and its introductory chapter is by HB Stoner on the responses to injury, past research, and future plans.

In both volumes the great majority of the papers are based on animal experiments, though there are notable exceptions concerned with human studies. Unfortunately the contents lists have been placed in the wrong books which makes for a little confusion. It is clear that the shock models used at the present time are much the same as they were 30 years ago, and it is still difficult to conclude that results obtained in mice are automatically referable to man. Nevertheless, there are some interesting papers on organ responses and on trials of newer pharmacological agents. The editorial work was divided up for the two volumes and was adequate in both cases. The publishers have requested reviewers to state that for readers in the United Kingdom, Europe, and the Middle East the books are available through European Book Service, each volume at the equivalent of 90 Dutch guilders. The volumes are primarily for those involved in one or other aspects of the shock field, which includes many clinicians and too few pathologists.

SIMON SEVITT

Contributions to Nephrology. Vol 17. 'Today's Art of Peritoneal Dialysis'. Ed A Trevino-Becerra and FST Boen. (Pp $x+150$; illustrated; Sw Fr 75.) Basel: S Karger. 1979.

This book, although not of primary interest to clinical pathologists, is nonetheless an important development in the field of renal failure. Peritoneal dialysis, after being very much a temporary form of treatment, has now come into its own again with the advent of suitable equipment and techniques for chronic ambulatory peritoneal dialysis at home. In this era of increasing financial restriction this can only be of considerable interest to nephrologists all over the world. The book is the proceedings of a symposium bringing together experts in the field. A number of groups describe their experience in using chronic peritoneal dialysis both in hospital and at home and show a surprisingly low incidence of serious complications. A problem of the past, protein loss, seems now to have been largely conquered by adequate diet and suitable infusion fluids. Advances in technology have diminished the risk of infections.

The use of peritoneal dialysis in the treatment of drug poisoning is summarised as a short but useful paper. A number of papers are devoted to the more basic aspects such as the effect of dialysis solutions on the microcirculation, on models for predicting transport of molecules across the peritoneum, and on nitrogen metabolism in patients with peritoneal dialysis. A useful and comprehensive paper describes the dietary management of patients on peritoneal dialysis.

In summary it may be said that this book highlights an important redevelopment in the management of patients with chronic renal disease but does in fact contain a fair amount of repetitious material, particularly in the papers describing the experience of a number of different groups in managing patients by this technique. However, the book will be of considerable interest to pathologists directly involved with such patients, particularly chemical pathologists.

JT WHICHER

Atlas of Laparoscopy and Biopsy of the Liver. M Bruguera, JM Bordas, and J Rodes. (Pp xii + 215; illustrated; $£ 32 \cdot 50$.) Philadelphia, London, Toronto: WB Saunders. 1979.

A number of atlases on various aspects of hepatology have appeared recently, directed at clinician and pathologist alike, and they appear to have enjoyed considerable success. The present text is a further addition along these lines, combining the macroscopic appearances of the liver as seen at laparoscopy with the microscopic appearances seen on needle biopsy material. It represents the work of the distinguished hepatology unit of the Faculty of Medicine at the University of Barcelona. To a morbid anatomist, familiar only with the dull macroscopic appearances as seen at necroscopy, the laparoscopic illustrations in the book have been a vital and visual delight. It does seem a pity that laparoscopic examination of the liver has been used on only a very limited scale in this country; the advantages to be derived from direct visualisation and from dire biopsy under these conditions would seem to be considerable. The coloured phot micrographs are not of the same uniformy high standards as the laparoscopic illus: trations, and in this aspect the atlas perhaps less distinguished than othe? available. As is almost inevitable wi translated books, the text is a little stilted in parts. It is irritating to find reticulin, reticulum, and reticular appearing $\overrightarrow{a s}$ freely interchangeable variations on thet same theme.

\section{IMPORTANT CORRECTION}

Microbial Disease; the use of the labo oratory in diagnosis, therapy, and controf DAJ Tyrrell, I Phillips, C Steward Goof win, and $R$ Blowers. (Pp $x+346$; illustrated ; 116.00 .) Edward Arnold, 1979

This book was reviewed in the Januar issue (J Clin Pathol 1980;33:99). The publishers draw attention to the followin correction:

page 279 under heading Treatmen line 5: delete the words 'or intraveno ously'.

page 293 six lines from the bottom: fót $700 \mathrm{~m}^{3}$ read $7 \mathrm{~m}^{3}$.

All books should be returned to:

Mr M Husk (Trade Department),

Edward Arnold (Publishers) Ltd,

Woodlands Park Avenue,

Woodlands Park,

Maidenhead, Berks.

They will be corrected and returned wit a refund of postage. 